\title{
Successful endoscopic management of large upper gastrointestinal perforations following EMR using over-the-scope clipping combined with stenting
}

Large iatrogenic gastrointestinal perforations (greater than 15-20 mm) following therapeutic endoscopy remain a challenge despite growing expertise in endoscopic perforation closure techniques. Current treatment options include stenting $[1,2]$ or clipping, including the use of an over-the-scope clipping device [3-5]. We present our experience using a combination of over-the-scope clipping and stenting for the treatment of challenging large iatrogenic gastrointestinal perforations.

In our first case, a 70-year-old man with a 20-cm-long Barrett esophagus underwent endoscopic mucosal resection (cap suction technique) of a $15-\mathrm{mm}$ early neoplasm situated in the distal esophagus. Following resection, a $20-\mathrm{mm}$ perforation was observed. Under $\mathrm{CO}_{2}$ insufflation, endoscopic closure was attempted using a large 12-mm sharp-tooth OTSC clip (OVESCO Endoscopy AG, Tübingen, Germany), followed by placement of a fully covered stent ( Video 1, $\bullet$ Fig. 1). Contrast fluoroscopy at 1 week demonstrated no signs of leakage nor stent migration. The patient recovered well despite developing pleural effusion needing thoracic drainage and antibiotic therapy. The esophageal stent was removed after 6 weeks and adequate healing of the perforated site was confirmed.

In the second case, a 68-year-old man with a $35-\mathrm{mm}$ elevated duodenal lesion underwent successful free-hand piecemeal snare resection. Three days after the procedure the patient presented with localized retroperitoneal soiling. A large duodenal perforation was identified ( $\bullet$ Fig.2) and was initially treated with placement of a fully covered stent fixed to the antrum with several clips to avoid migration. Three days later the stent migrated. After removal of the stent, an OTSC clip was placed along with two other standard clips (under $\mathrm{CO}_{2}$ insufflation) to ensure full-length closure of the perforation. Another fully covered stent was again placed over the perforation, and no fixation was required ( $\mathrm{Fig} .3$ ). The patient recovered well with the stent in place. After 8 weeks the stent was removed, revealing a deep scar.

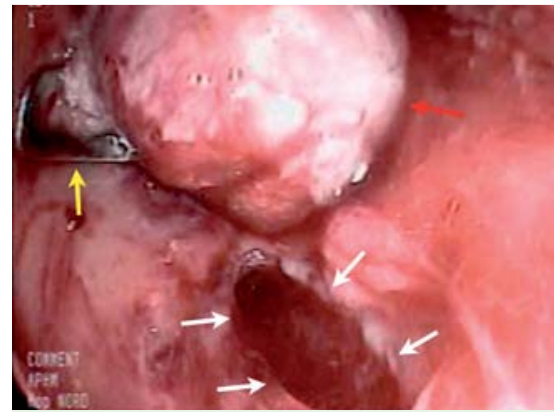

Fig. 1 Endoscopic view of a large 20-mm esophageal perforation after successful placement of an over-the-scope clipping device (yellow arrow). Although a large piece of tissue from the margins has been trapped to ensure full-thickness closure (red arrow), a remaining open area can be seen (white arrows).

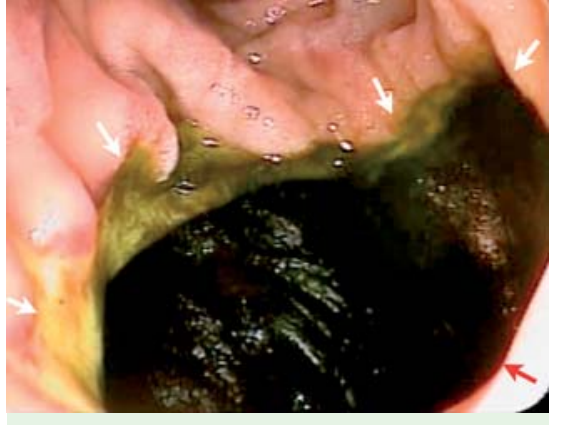

Fig. 2 Endoscopic view of a large 40-mm perforation 3 days after endoscopic mucosal resection localized at the second portion of the duodenum. No underlying fat tissue was available to assist closure.

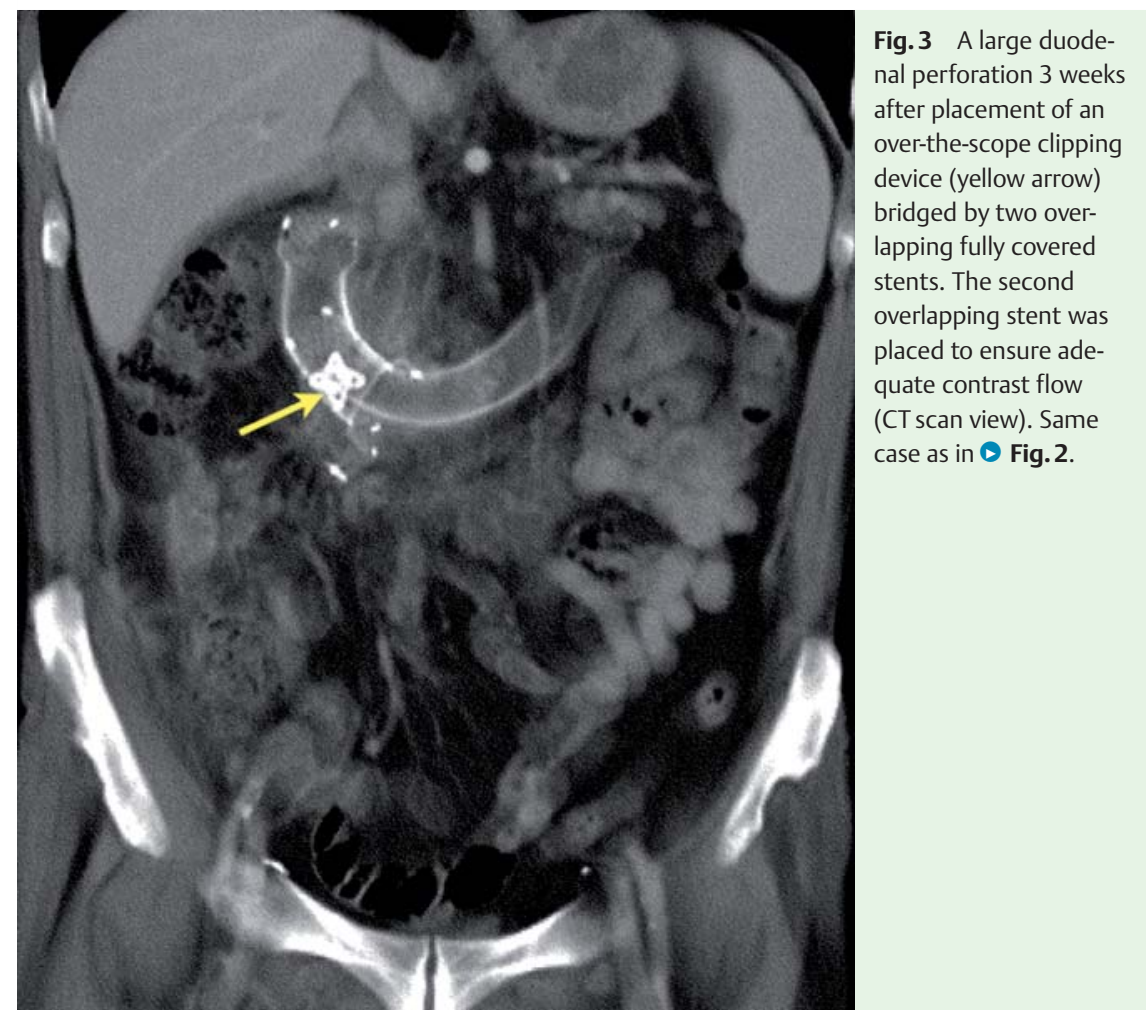

Endoscopy_UCTN_Code_TTT_1AO_2AZ

Competing interests: None
Video 1

Complete closure of the esophageal perforation is achieved using an OTSC clip (OVESCO Endoscopy AG, Tübingen, Germany) and several other standard clips joined together with an endoloop. Then, a fully covered stent is placed, bridging the perforation. 
W. B. Hadj Amor, E. A. Bonin, V. Vitton, A. Desjeux, J.-C. Grimaud, M. Barthet

Department of Gastroenterology, Endoscopy Unit, Hôpital Nord, Marseille, France

\section{References}

1 Amrani L, Ménard C, Berdah S et al. From iatrogenic digestive perforation to complete anastomotic disunion: endoscopic stenting as a new concept of "stent-guided regeneration and re-epithelialization". Gastrointest Endosc 2009; 69: 1282-1287
2 Raju GS. Gastrointestinal perforations: role of endoscopic closure. Curr Opin Gastroenterol 2011; 27: 418-422

3 Parodi A, Repici A, Pedroni A et al. Endoscopic management of GI perforations with a new over-the-scope clip device (with videos). Gastrointest Endosc 2010; 72: 881 - 886

4 Coriat $R$, Leblanc S, Pommaret E et.al. Endoscopic management of endoscopic submucosal dissection perforations: a new overthe-scope clip device. Gastrointest Endosc 2011; 73: 1067-1069

5 Buffoli F, Grassia R, Iiritano E et al. Endoscopic "retroperitoneal fatpexy" of a large ERCP-related jejunal perforation by using a new over-the-scope clip device in Billroth II anatomy (with video). Gastrointest Endosc 2012; 75: 1115-1117
Bibliography

DOI http://dx.doi.org/ 10.1055/s-0032-1309861

Endoscopy 2012; 44: E277-E278

(c) Georg Thieme Verlag KG

Stuttgart · New York

ISSN 0013-726X

\section{Corresponding author}

\section{Barthet, MD}

Department of Gastroenterology Hôpital Nord

Chemin des Bourrely

13915 Marseille cedex 20

France

Fax: +33-4-91961311 